\title{
Recent advances in pediatric bladder malignancies [version 1;
}

\section{peer review: 2 approved]}

\author{
Roberto Iglesias Lopes (D1), Marcos Figueiredo Mello (D1), Armando J. Lorenzo² \\ 1Pediatric Urology Unit, Division of Urology, Hospital das Clínicas, University of São Paulo Medical School, São Paulo, 05402-000, \\ Brazil \\ ${ }^{2}$ Division of Urology, The Hospital for Sick Children and Department of Surgery, University of Toronto, Toronto, ON, Canada
}

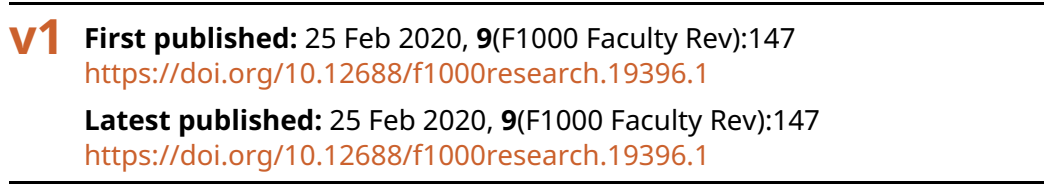

\section{Abstract}

Urothelial pediatric neoplasms are relatively rare. Papillary urothelial neoplasms of low malignant potential (PUNLMPs) and rhabdomyosarcoma (RMS) are the most common bladder malignancies in the pediatric population. Clinical presentation encompasses macroscopic hematuria or lower urinary tract symptoms (or both) or is detected incidentally at imaging. Tumors arising from the bladder can originate from any of its four histological layers (urothelium, lamina propria, detrusor, and adventitia) and are divided into tumors that have an epithelial origin (arising from the urothelium) and those that have a non-epithelial origin (mesenchymal neoplasms). RMS is the most common malignant tumor of the urinary bladder in children younger than 10 years. Deriving from the embryonic mesenchymal cell, the histopathologic subtypes of RMS are embryonal RMS (>90\%) and alveolar histology (<10\%). Pre-treatment imaging should be carried out by computed tomography (CT) or at present is more likely with magnetic resonance imaging of the pelvis. Chest CT and bone scintigraphy are used to screen for metastases. In selected cases, a positron emission tomography scan may be recommended to evaluate suspicious lesions. The current prognostic classification considers age, histologic subtype, tumor site, size, and extent (nodal or distant metastases). Staging is based on preoperative findings, group is based on intra-operative findings and pathology, and risk stratification is derived from both stage and group data. Pre-operative chemotherapy is the most common first-line intervention for bladder/prostate RMS, before surgery or radiation therapy. Collaborative groups such as the Soft Tissue Sarcoma Committee of the Children's Oncology Group and the European Pediatric Soft Tissue Sarcoma Study Group endorse this therapy. PUNLMPs are generally solitary, small (1-2 cm), non-invasive lesions that do not metastasize. Therapy is usually limited to a transurethral resection of the bladder tumor. About 35\% are recurrent and around $10 \%$ of them increase in size if they are not treated.

\section{Open Peer Review}

Approval Status

1 2

version 1

$25 \mathrm{Feb} 2020$

Faculty Reviews are review articles written by the prestigious Members of Faculty Opinions. The articles are commissioned and peer reviewed before publication to ensure that the final, published version is comprehensive and accessible. The reviewers who approved the final version are listed with their names and affiliations.

1. Harry W. Herr, Memorial Sloan Kettering Cancer Center, Weill-Cornell Medical College, New York, USA

2. Daniel Orbach, SIREDO oncology center (Care, Innovation and Research for Children, Adolescents and Young Adults with cancer), Institut Curie, PSL university, Paris, France Any comments on the article can be found at the end of the article. 
Keywords

PEDIATRIC, BLADDER MALIGNANCIES

Corresponding author: Marcos Figueiredo Mello (marcos.urologia@gmail.com)

Author roles: Lopes RI: Investigation, Project Administration, Writing - Original Draft Preparation, Writing - Review \& Editing; Mello MF: Investigation, Writing - Original Draft Preparation, Writing - Review \& Editing; Lorenzo AJ: Investigation, Project Administration, Supervision, Writing - Original Draft Preparation, Writing - Review \& Editing

Competing interests: No competing interests were disclosed.

Grant information: The author(s) declared that no grants were involved in supporting this work.

Copyright: $\odot 2020$ Lopes RI et al. This is an open access article distributed under the terms of the Creative Commons Attribution License, which permits unrestricted use, distribution, and reproduction in any medium, provided the original work is properly cited.

How to cite this article: Lopes RI, Mello MF and Lorenzo AJ. Recent advances in pediatric bladder malignancies [version 1; peer review: 2 approved] F1000Research 2020, 9(F1000 Faculty Rev):147 https://doi.org/10.12688/f1000research.19396.1

First published: 25 Feb 2020, 9(F1000 Faculty Rev):147 https://doi.org/10.12688/f1000research.19396.1 


\section{Introduction}

Bladder tumor occurrence and histological subtypes differ considerably between adults and children. Pediatric bladder neoplasms are relatively rare and-with the exception of rhabdomyosarcoma (RMS) - are associated with favorable benign behavior and outcomes after adequate therapy. The incidence does appear to be increasing, according to some studies such as data analyses between 1973 and 2003 using the Surveillance, Epidemiology and End Results (SEER) database. Papillary urothelial neoplasm of low malignant potential (PUNLMP) and RMS are the most common bladder malignancies in the pediatric population. Males were generally more affected than females with bladder malignancies (by a ratio of $2: 1)^{1}$.

Clinical presentation includes macroscopic hematuria or lower urinary tract symptoms or both (dysuria, frequent urination, incontinence, pelvic pain, and urinary retention) and a palpable suprapubic mass or is detected incidentally at imaging ${ }^{2}$.

Urinalysis and urinary culture are mandatory to exclude or confirm concomitant urinary tract infection. Owing to the low sensitivity (low cell turnover related to the benign nature of many pediatric bladder lesions) and the absence of experience of pediatric pathologists in such situations, urinary cytology is rarely useful ${ }^{2}$. Ultrasonography (US) is the most common initial examination: a full bladder during examination is advisable to avoid missing small lesions or making a misinterpretation ${ }^{3}$. If malignancy is suspected, pelvic computed tomography (CT) or-preferably-magnetic resonance imaging (MRI) is performed for better characterization of the location and extent of disease (Figure 1). A tissue biopsy is often necessary, usually through cystoscopic resection, since imaging alone is not able to predict histological subtypes (Figure 2). Work-up includes hemoglobin quantification in case of massive hematuria, assessment of inflammatory marker levels if suspicion of infection and determining renal function if bladder tumor is associated with hydronephrosis.

\section{Subtypes}

Tumors arising from the bladder can originate from any of its four layers (urothelium, lamina propria, detrusor, and adventitia) and are classified as tumors with an epithelial origin (urothelial tumors) or a non-epithelial origin (mesenchymal neoplasms) ${ }^{4}$. Urothelial neoplasms are rare in children. Non-invasive urothelial neoplasms are much more common in children than are invasive urothelial carcinomas 5 . Other relevant but rarer tumors in the pediatric population will also be discussed in this article.

\section{Mesenchymal neoplasms}

RMSs are malignant tumors deriving from the embryonic mesenchymal cell, which forms the striated musculature. In the genitourinary tract, RMS could affect the bladder, prostate, paratesticular region, uterus, and vagina. RMS is the third most common extracranial solid tumor of childhood (after Wilms' tumor and neuroblastoma). Overall, 15 to $20 \%$ of all RMSs arise from the genitourinary tract. RMS is also the most common malignant tumor of the urinary bladder in children younger than 10 years $^{1}$, accounting for $5 \%$ of all childhood solid cancers ${ }^{6}$. Males are more commonly affected than females with bladder malignancies (by a ratio of $2: 1)^{1}$. We assume that, in boys, genitourinary pelvic RMS originates mainly on the prostate and more rarely on the bladder, but owing to the initial extent of the tumor, RMS appears as a bladder prostate primary tumor in the literature. In females, genitourinary RMS originates mostly on the bladder but can rarely be primary from the vagina or uterus.

Genitourinary pelvic RMSs have a bimodal age distribution; the peak incidence occurs within the first 2 years of life $(>50 \%$ of cases, mostly embryonal or botryoid RMS) and another peak occurs during adolescence (mostly alveolar RMS) ${ }^{6}$. Age of diagnosis is an important risk factor for genitourinary pelvic RMS: rates of event-free survival (EFS) are 53\% for those who are less than 1 year or more than 10 years old and $71 \%$ for those who are 1 to 9 years old ${ }^{7}$. Sporadic tumors are much more
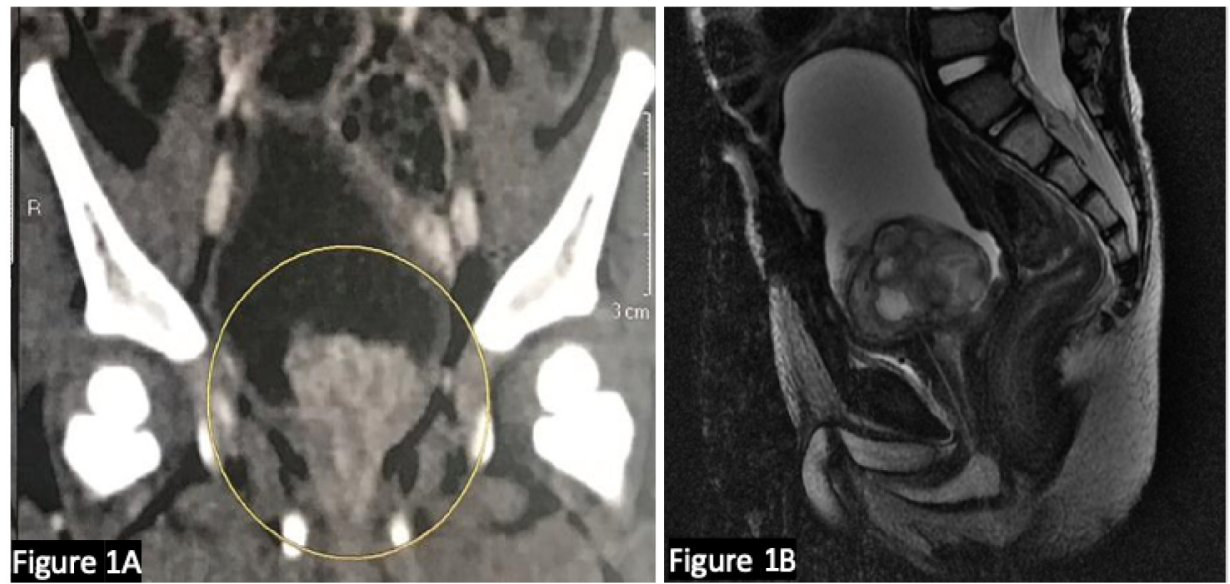

Figure 1. Computed tomography and magnetic resonance images of tumor. (A) Computed tomography depicting bladder tumor at the trigone. (B) Magnetic resonance image showing better characterization of location and extent of the tumor. We confirm that the patients gave us permission to use these images. 
frequent (90\% of all cases), but association with genetic syndromes should be considered (Li-Fraumeni, neurofibromatosis type 1, multiple endocrine neoplasia type 2A, and DICER1 germline pathologic variant, especially in pelvic female RMS) ${ }^{8,9}$.

The histopathologic subtypes of RMS include embryonal RMS (>70-90\% of cases), are more common in children younger than 10 years of age, and have a favorable prognosis. The alveolar histology $(<10-30 \%$ of cases $)$ is more frequent in

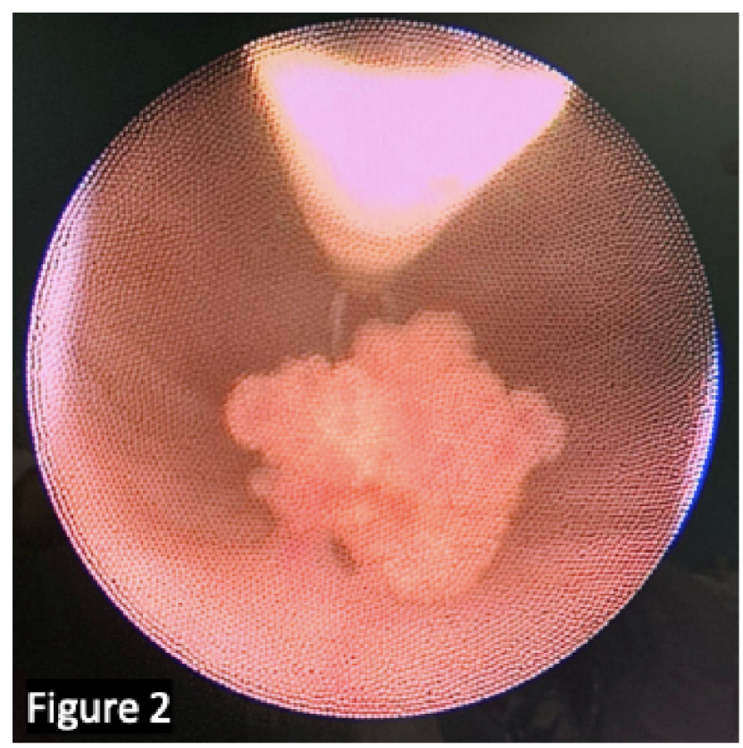

Figure 2. Transurethral resection of a solitary, non-muscle invasive, and low-grade papillary urothelial neoplasms of low malignant potential. We confirm that the patient gave us permission to use this image. adolescents and confers a lower chance of cure. Macroscopically, these lesions are typically polypoid and gelatinous when they occur in cavities and multilobulated when they are of the botryoid subtype, as shown in Figure 3. Microscopically, the embryonal subtype consists of small, dark, spindle-shaped, or round cells with minimal cytoplasm, mixed with a variable number of cells resembling rhabdomyoblasts. The alveolar subtype is characterized by thin septae lined by a single layer of cuboidal tumor cells with hyperchromatic nuclei resembling alveolar airspaces ${ }^{10}$.

Pre-treatment imaging preferably should be carried out by CT or MRI of the pelvis and abdomen for nodal area evaluation. The chest should be evaluated by CT. Bone scintigraphy is useful for screening for osseous metastases. Positron emission tomography CT (PET-CT) scan is progressively being used instead in the evaluation of this neoplasm. Bone marrow biopsies are also needed.

After initial work-up, extirpative surgery is indicated for patients whose tumors are localized and amenable to complete resection with minimal morbidity, which is really uncommon in bladder primary neoplasms: only about $12 \%$ are likely to be amenable to complete excision at presentation ${ }^{10}$. Pelvic and retroperitoneal nodes at the renal artery or below can be affected. Bladder function can be saved in up to $60 \%$ of cases by partial cystectomy: while dome tumors are easily resected, lower or extensive lesions require reimplantation of ureters or bladder augmentation (or both) or a neobladder ${ }^{11-13}$.

Stratification of the risk of RMS is based on a pre-treatment TNM (tumor-lymph nodes-metastasis) staging system and a post-biopsy and resection clinical grouping system established by the Intergroup Rhabdomyosarcoma Study Group (IRS-G), now contained within the Children's Oncology Group (COG)

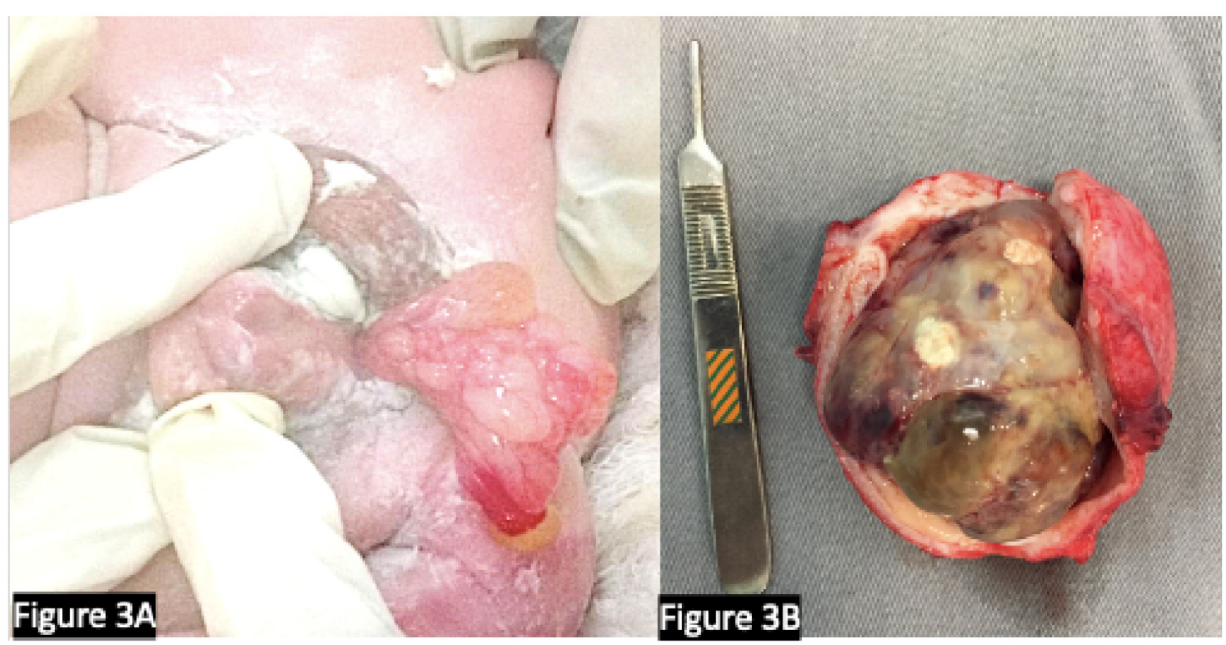

Figure 3. Cases of rhabdomyosarcoma. (A) A male infant at 14 months with congenital rhabdomyosarcoma protruding through the urethra Note the association with a proximal hypospadias. (B) Cystoprostatectomy specimen showing extensive rhabdomyosarcoma with necrosis after neoadjuvant chemotherapy. (Surgery was performed for the tumor depicted in frame $\mathbf{B}$.) We confirm that the patients gave us permission to use these images. 
Soft Tissue Sarcoma Committee. Through the performance of several multicenter randomized trials, this Committee classified the RMS more accurately by tailoring treatment to optimize cancer outcome and minimize treatment-related effects. The current challenge is the risk stratification of tumors by biological characteristics to provide targeted therapies ${ }^{14,15}$.

The COG classification is divided into pre-treatment staging and clinical groups (Table 1). Pre-treatment staging is based on size, site, and extent of the tumor (nodal or distant metastases), and clinical groups are divided on pre- and intra-operative findings. Risk groups take all of these data into account along with pathology and biologic behavior analysis (Table 2). Localized embryonal RMS has a better prognosis with an $80 \%$ 5-year EFS rate, whereas the alveolar subtype is associated with a $65 \% 5$-year EFS rate re, $^{14}$.

Quality of the surgery has a major impact on local disease control and correlates with the prognosis. IRS clinical groups are used for disease classification and prognosis (Table 1). European Pediatric Soft Tissue Sarcoma Study Group (EpSSG) stratification is composed of four risk groups: (1) low risk: small tumors $(<5 \mathrm{~cm})$, completely resected at diagnosis (IRS group I) with favorable histology (embryonal, botryoid); (2) intermediate risk: resected at diagnosis with microscopic residual disease (IRS group II) with favorable histology (embryonal, botryoid);
(3) high risk: large IRS group III tumors $(>5 \mathrm{~cm}$ ) with or without nodal involvement or alveolar subtype or both; (4) very high risk: metastatic disease (IRS group IV).

Collaborative groups (COG and EpSSG) offer multimodal treatment-local therapy (radiotherapy or surgery) and chemotherapy-in an attempt to improve outcome whilst finding the correct balance between the intensity of treatment and its possible cost in terms of late effects.

If tumor resection is not possible (for instance, when excision with clear margins will cause functional impairment or mutilation), a diagnostic biopsy is required.

Group I: completely resected disease and can be treated with surgery only or by additional post-operative chemotherapy. Chemotherapy based on vincristine, actinomycin, cyclophosphamide (VAC) or ifosfamide, vincristine, actinomycin (IVA) combinations is the most common first-line intervention in COG. The EpSSG protocol advised only for vincristine, actinomycin (VA) regimen to reduce long-term gonadal toxicity of alkylating agents.

Group II: resected tumor with microscopic residual disease. Need of further treatment is unclear in this scenario. Nevertheless, as for all RMSs, adjuvant chemotherapy is usually required, and radiation therapy is often applied.

\section{Table 1. Intergroup Rhabdomyosarcoma Study clinical groups and pre-treatment staging (bladder only).}

\begin{tabular}{|l|l|l|l|}
\hline \multicolumn{2}{|l|}{ Pre-treatment staging } & \multicolumn{2}{l|}{ Clinical groups } \\
\hline 1 & $\begin{array}{l}\text { None of bladder tumors fall in this category } \\
\text { Only genitourinary sites (other than bladder and/or prostate) }\end{array}$ & I & Completely resected, no evidence of metastatic disease \\
\hline 2 & $\leq 5 \mathrm{~cm}$, negative lymph nodes and no metastases & II & $\begin{array}{l}\text { IIA. Microscopic residual disease after complete gross resection } \\
\text { IIB. Positive lymph nodes with no residual disease }\end{array}$ \\
\hline 3 & \begin{tabular}{l} 
IIC. Positive lymph node with microscopic residual disease \\
\hline \\
\hline 4
\end{tabular} & III & Gross residual disease \\
\hline
\end{tabular}

Table 2. Current Children's Oncology GroupSoft Tissue Committee risk stratification for rhabdomyosarcoma (bladder only).

\begin{tabular}{|l|l|l|l|}
\hline Risk group & $\begin{array}{l}\text { Pre-treatment } \\
\text { stage }\end{array}$ & $\begin{array}{l}\text { Clinical } \\
\text { group }\end{array}$ & Histology \\
\hline Low & 2 & I-II & Embryonal \\
\hline & 3 & I-II & Embryonal \\
\hline Intermediate & $2-3$ & III & Embryonal \\
\cline { 2 - 4 } & $2-3$ & I-III & Alveolar \\
\hline High & 4 & IV & Embryonal \\
\hline & 4 & IV & Alveolar \\
\hline
\end{tabular}


Group III: gross residual disease after resection, which is the most common situation. Usually, it presents with an unsatisfactory prognosis, and adjuvant local treatment after chemotherapy is a point of debate and study; EpSSG places more emphasis on surgery, and COG on radiation therapy.

Radiation therapy is frequently needed and commonly employed. In general, this is employed for the following cases: (1) unresectable residual tumor, (2) residual disease following surgery, (3) nodal disease, and (4) alveolar histology. There is considerable debate regarding what the best strategy for local control should be. With the ultimate goal of organ preservation, surgery and radiation therapy offer different risks and benefits. Although radiation often allows for lower initial morbidity and preservation of the affected organ, the long-term effects from radiation remain worrisome, especially in young boys (median age of this disease is 2 years old $)^{16}$. On the other hand, surgery often requires aggressive resection and reconstruction that relies on bladder substitution and need for catheterization. Furthermore, the implications of radiation after surgery and surgery after radiation are debatable, and both generate important concerns in patients who fail the primary local control modality. These issues will persist until data from multi-institutional groups mature. Brachytherapy is a good alternative to apply radiation therapy on the pelvis and is gaining traction in some parts of the world. As a general principle, a conservative strategy must be preferred with partial cystectomy and radiotherapy, rather than radical cystectomy. As long-term effects with brachytherapy appear to be reduced in comparison with external radiotherapy, this technique must be considered, especially in young patients. Proton therapy may replace brachytherapy if the latter technique is not available.

Group IV: metastatic disease that presents a poor prognosis with an overall survival rate of 20 to $30 \%$ and whose management has not improved over time; therefore, experimental approaches are needed for these patients ${ }^{17}$.

Surveillance imaging (for at least 5 years) is recommended for patients. The disease recurs in up to a third of the patients, and $95 \%$ of relapses occur within 3 years ${ }^{12,13}$.

\section{Inflammatory myofibroblastic bladder tumors}

Inflammatory myofibroblastic tumors of the bladder (IMTBs) are rare (a quarter of these neoplasms occur in children) and are characterized by a benign and reactive proliferation of myofibroblasts. A review of 42 reported cases of pediatric IMTB showed equal prevalence in males and females. Clinical presentation includes hematuria, dysuria, or abdominal pain, and mean age at presentation is 7.5 years (range of 2 to 15 years). The etiology of IMTB is poorly understood and is attributed to infectious or traumatic causes or a possible clonal lesion mainly involving the anaplastic lymphoma kinase gene $(A L K-1)$ or NTRK, ROS1 PDGFR, and NTRK, which are far more common in children and young adults ${ }^{16}$.

Lesions range in size from 1.8 to $13 \mathrm{~cm}$, and the mean size is $5.5 \mathrm{~cm}$ in the largest diameter. Lesions may be pedunculated, nodular, lobular, or frond-like in appearance. The commonest sites of IMTBs are the dome of the bladder in children and the lateral bladder wall in adults. Tissue biopsy is essential for diagnosis. Immunohistochemistry ALK-1 expression is useful in the diagnosis of IMTB but is not always present ${ }^{16}$. Nowadays, systematic RNA sequencing is needed to confirm this diagnosis.

Complete surgical resection of the lesion is the treatment of choice. In children, no proven recurrent/metastatic IMTB has been reported, but follow-up is warranted as recurrent IMTB was previously reported in adults ${ }^{16}$. For treatment of unresectable IMTB, no clear recommendation has been defined, the role of chemotherapy is a topic of controversy, and anecdotal experience suggests that non-steroidal anti-inflammatory drugs (NSAIDs) may shrink large IMTBs to a more readily resectable size and configuration or eradicate them altogether. It is hypothesized that NSAIDs interfere with vascular endothelial growth factor (VEGF) signaling via inhibition of cyclooxygenase 2 (Cox-2). Target therapies possibly help to induce regression of neoplastic inflammatory masses via three different mechanisms: (1) suppression of the VEGF angiogenesis stimulation (Cox-2/prostaglandin/VEGF pathway), (2) direct inhibition of the proliferation of activated endothelial cells in which Cox-2 is known to be expressed, and (3) an anticytokine suppression effect on the inflammatory process ${ }^{16-19}$. There are other drug options, such as vinblastine and low-dose methotrexate $^{18}$. The armamentarium of systemic therapies has changed in our study period, and the role of classic chemotherapy should be discussed in light of the availability and efficacy of tyrosine kinase inhibitors for unresectable tumors or in case of predicted mutilating surgery.

\section{Leiomyoma}

Bladder leiomyomas are rare, accounting for less than $1 \%$ of all mesenchymal bladder tumor subtypes, and are exceedingly rare in children. Clinical presentation includes urinary obstruction, frequent urination, dysuria, and hematuria ${ }^{20}$. Characteristically, these lesions are a solitary, homogeneously attenuating mass. Excision is curative and carries no risk of recurrence or metastasis.

\section{Neuroendocrine tumors}

Paraganglioma. The origin of bladder paragangliomas is related to the embryonic rests of chromaffin cells in the sympathetic plexus of detrusor muscle. These tumors are exceedingly rare $(<0.5 \%$ of all bladder tumors in adults and children combined).

Bladder paragangliomas are usually benign, but $10 \%$ may be malignant (often hormonally active). Clinical presentation might be related to catecholamine excess, including hypertension and headache, sometimes related to micturition ${ }^{21,22}$.

Paragangliomas tend to be vascular tumors with avid enhancement characteristics at MRI. A PET scan may be employed to confirm diagnosis and to identify metastatic lymph nodes. Pre-operative care-including adrenergic blockade-is necessary to avoid an intra-operative hypertensive crisis. Surgical resection is usually curative $\mathrm{e}^{21,22}$. 
Neurofibroma. Up to $75 \%$ of bladder neurofibromas are detected in children, and the bladder is the most common genitourinary site for these tumors. Bladder wall spinal and autonomic nerves can be involved. Patients can be completely asymptomatic or present voiding dysfunction. Bladder tumors may be the first manifestation of neurofibromatosis type 1 (NF1), and the cutaneous stigmata of the syndrome is occasionally identified $^{23,24}$.

Neurofibroma usually is depicted as a benign solid mass (focal lesion or diffuse bladder wall thickening). Homogeneous low signal intensity on T1-weighted images and high signal intensity on T2-weighted images are the most common patterns at $\mathrm{MRI}^{23,24}$. Differential diagnosis includes RMS and paraganglioma. Debulking resection provides symptom relief, as complete resection is difficult because of the plexiform nature of these neoplasms. Malignant transformation of neurofibromas in a malignant peripheral nerve sheath tumor is rare but should be considered in case of pain or a rapidly growing tumor or both.

The response to chemotherapy or radiotherapy is poor, and the majority of cases of NF1 with bladder dysfunction are managed by surgery. Surgery has inherent complications in these patients. Immunosuppression and chemotherapy increase the risk of infection, the need for extensive resection of these tumors leads to significant lymphedema, and skin invasion or malnutrition exposes these patients to poor healing. Because complete resection of genitourinary plexiform neurofibromas is often difficult, non-continent urinary diversions are the method of choice ${ }^{25}$.

The best long-term outcome following malignant transformation is achieved after complete resection with clear margins. This means that, when malignization appears during follow-up, surgery must be proposed without delay ${ }^{26}$.

\section{Vascular tumors}

In children, vascular tumors are exceedingly rare within the bladder and usually manifest as painless recurrent macroscopic hematuria ${ }^{27,28}$. Sonographically, vascular tumors may present as a polypoid solid mass with increased vascularity or less commonly as a diffuse bladder wall thickening. Usually, these tumors are solitary and are seen at the bladder dome or the posterolateral bladder walls. Syndromes such as KlippelTrénaunay-Weber, Sturge-Weber, and Proteus are associated with tumor multiplicity ${ }^{27,28}$.

Ablative treatment is the standard of care; a partial cystectomy may be necessary for large tumors. Sclerotherapy has emerged as an option of bladder hemangioma management following a successful experience with this method in other body sites.

Lymphatic and arteriovenous malformations and bladder wall telangiectasia (in the setting of ataxia-telangiectasia) are differential diagnosis. Epithelioid hemangioendothelioma and angiosarcoma should be considered in aggressive cases ${ }^{27,28}$.

\section{Urothelial neoplasms}

Urothelial neoplasms in children are rare and predominantly non-invasive. Lesions were classified in accordance with the 2004 World Health Organization/International Society of Urological Pathology criteria as urothelial papillomas (UPs), PUNLMPs, and low-grade urothelial carcinomas and high-grade urothelial carcinomas.

At presentation, the most common symptom is painless hematuria. In the presence of hematuria, US must be performed. If a bladder lesion is identified, transurethral resection of the bladder should be performed. The lesions are usually solitary, non-muscle invasive, and of low grade (mainly UPs and PUNLMPs) (Figure 2). There is no ideal follow-up protocol. Recurrence or progression is uncommon in patients younger than 20 years, the reported recurrence rate is $7 \%$, and a single case of progression has been reported so $\operatorname{far}^{29,30}$.

Papillary urothelial neoplasm of low malignant potentials. PUNLMPs are common bladder lesions in children and are used to describe a urothelial tumor that resembles exophytic urothelial. They are normally solitary and small (1-2 cm), commonly occur at the posterior lateral walls and ureteric orifices of the bladder, are non-invasive, and do not metastasize. About $35 \%$ of PUNLMPs reportedly recur after complete resection, and around $10 \%$ of them increase in size if they are not treated; therefore, regular imaging surveillance is advocated ${ }^{29,30}$.

Urothelial papilloma. UPs are benign polypoid urothelial neoplasms that are infrequently reported in children. Microscopically, a broad vascular core covered by a normal urothelium and no cytologic atypia is the pattern.

UPs have a frond-like appearance in imaging. Transurethral excision is the treatment of choice. Because UPs seen in adults are known to recur, US follow-up has been advocated ${ }^{29,30}$.

Urothelial carcinoma. Urothelial carcinomas are rare and, in children, have a different clinical course. Most of these tumors are solitary, have a low-grade morphology, are associated with a low risk of recurrence, and seldom involve the upper urinary tract. They are much more common in adolescents; only $30 \%$ of cases occur in children who are 10 years old or younger ${ }^{29,30}$.

Urothelial carcinoma may occur in childhood cancer-predisposing syndromes such as Costello syndrome and hereditary non-polyposis colorectal cancer syndrome. Augmented bladders have an increased risk of developing urothelial carcinoma, usually at bladder-intestinal anastomosis, and these tumors are frequently of high grade and have a more aggressive behavior ${ }^{27,29,30}$.

No criteria have been established for treatment and follow-up for these children with urothelial carcinomas. For most patients, treatment is transurethral resection of the bladder tumor (TURBT). There is no recommendation of adjuvant therapy following resection as these tumors are rare in a pediatric age group. Some authors have performed partial cystectomy instead 
of TURBT in view of the risk of perforation of the pediatric bladder. Some reports also have given treatment with mitomycin $\mathrm{C}$ along with TURBT. There is no standard surveillance protocol for the imaging follow-up of patients who have received treatment, and recurrences have been reported, especially in cases with multiple tumors ${ }^{29-31}$.

\section{Nephrogenic adenoma}

Nephrogenic adenoma (NA) of the urinary bladder is a metaplastic change in the urinary bladder and has papillary or cryptic structures similar to those seen in renal tubules. Microscopically, NA consists of small to medium tubules, cysts, or papillae coated by cuboid epithelium to low columnar epithelium with eosinophilic cytoplasm. Genitourinary trauma and chronic inflammation are factors that predispose patients to exfoliation of renal tubular cells, leading to sowing in the urinary tract, especially to the urinary bladder. Several patterns of growth (tubular, cystic, tubulocystic, papillary, and flat) have been reported in isolation or combined (mixed morphology) ${ }^{32}$.

NAs, in contrast to other bladder tumors, commonly manifest with frequent urination rather than hematuria. For treatment, removal of the causative factors and excision of the lesion are required ${ }^{32}$.

\section{Urachal adenocarcinoma}

Urachal anomalies are thought to be associated with an increased risk of bladder adenocarcinoma in adults. Urachal anomalies are found incidentally in about $1 \%$ of children, and most anomalies are asymptomatic urachal remnants. The incidence of urachal malignancy in adults is extremely low (0.18 per 100,000 individuals yearly), and there is only one case described of urachal adenocarcinoma in childre ${ }^{26}$. It is therefore questionable that prophylactic resection of incidental urachal remnants plays a role in preventing future malignancies ${ }^{33}$.
1. Alanee S, Shukla AR: Bladder malignancies in children aged $<\mathbf{1 8}$ years: results from the Surveillance, Epidemiology and End Results database. BJU Int. 2010; 106(4): 557-60.

PubMed Abstract | Publisher Full Text

2. Dénes FT, Duarte RJ, Cristófani LM, et al:: Pediatric genitourinary oncology. Front Pediatr. 2013; 1: 48.

PubMed Abstract | Publisher Full Text | Free Full Text

3. F Mbeutcha A, Lucca I, Mathieu R, et al:: Current Status of Urinary Biomarkers for Detection and Surveillance of Bladder Cancer. Urol Clin North Am. 2016; 43(1): 47-62.

PubMed Abstract | Publisher Full Text | F1000 Recommendation

4. Shelmerdine SC, Lorenzo AJ, Gupta AA, et al.: Pearls and Pitfalls in Diagnosing Pediatric Urinary Bladder Masses. Radiographics. 2017; 37(6): 1872-91. PubMed Abstract | Publisher Full Text

5. Wong-You-Cheong JJ, Woodward PJ, Manning MA, et al:: From the Archives of the AFIP: neoplasms of the urinary bladder: radiologic-pathologic correlation. Radiographics. 2006; 26(2): 553-80.

PubMed Abstract | Publisher Full Text

6. Leaphart C, Rodeberg D: Pediatric surgical oncology: management of rhabdomyosarcoma. Surg Oncol. 2007; 16(3): 173-85. PubMed Abstract | Publisher Full Text

7. Joshi D, Anderson JR, Paidas C, et al.: Age is an independent prognostic factor in rhabdomyosarcoma: a report from the Soft Tissue Sarcoma Committee of the Children's Oncology Group. Pediatr Blood Cancer. 2004; 42(1): 64-73. PubMed Abstract | Publisher Full Text

8. Loeb DM, Thornton K, Shokek O: Pediatric soft tissue sarcomas. Surg Clin North Am. 2008; 88(3): 615-27, vii.

PubMed Abstract | Publisher Full Text | Free Full Text

9. $\quad \mathrm{F}$ Merideth MA, Harney LA, Vyas N, et al.: Gynecologic and reproductive health in patients with pathogenic germline variants in DICER1. Gynecol Oncol. 2020; pii: S0090-8258(19)31867-0.

PubMed Abstract | Publisher Full Text | F1000 Recommendation

10. Naini S, Etheridge KT, Adam SJ, et al:: Defining the cooperative genetic changes that temporally drive alveolar rhabdomyosarcoma. Cancer Res. 2008; 68(23): 9583-8.

PubMed Abstract | Publisher Full Text | Free Full Text

11. Rodeberg DA, Anderson JR, Arndt CA, et al:: Comparison of outcomes based on treatment algorithms for rhabdomyosarcoma of the bladder/prostate: combined results from the Children's Oncology Group, German Cooperative Soft Tissue Sarcoma Study, Italian Cooperative Group, and International Society of Pediatric Oncology Malignant Mesenchymal Tumors Committee. Int J Cancer. 2011; 128(5): 1232-9.

PubMed Abstract | Publisher Full Text

12. Cecchetto G, Carretto E, Bisogno G, et al.: Complete second look operation and radiotherapy in locally advanced non-alveolar rhabdomyosarcoma in children: A report from the AIEOP soft tissue sarcoma committee. Pediatr Blood Cancer. 2008; 51(5): 593-7.

PubMed Abstract | Publisher Full Text

13. Rodeberg D, Paidas C: Childhood rhabdomyosarcoma. Semin Pediatr Surg. 2006; 15(1): 57-62.

PubMed Abstract | Publisher Full Text

14. Raney RB, Anderson JR, Barr FG, et al:: Rhabdomyosarcoma and undifferentiated sarcoma in the first two decades of life: a selective review of intergroup rhabdomyosarcoma study group experience and rationale for Intergroup Rhabdomyosarcoma Study V. J Pediatr Hematol Oncol. 2001; 23(4): 215-20.

PubMed Abstract | Publisher Full Text

15. Crist WM, Anderson JR, Meza JL, et al.: Intergroup rhabdomyosarcoma studyIV: results for patients with nonmetastatic disease. J Clin Oncol. 2001; 19(12): 3091-102.

PubMed Abstract | Publisher Full Text

16. $\mathrm{F}$ Martelli $\mathrm{H}$, Borrego $\mathrm{P}$, Guérin $\mathrm{F}$, et al:: Quality of life and functional outcome of male patients with bladder-prostate rhabdomyosarcoma treated with conservative surgery and brachytherapy during childhood. Brachytherapy. 2016; 15(3): 306-11.

PubMed Abstract | Publisher Full Text | F1000 Recommendation

17. F Chisholm JC, Merks JHM, Casanova M, et al:: Open-label, multicentre, randomised, phase II study of the EpSSG and the ITCC evaluating the addition of bevacizumab to chemotherapy in childhood and adolescent patients with metastatic soft tissue sarcoma (the BERNIE study). Eur J Cancer. 2017; 83: metastatic

PubMed Abstract | Publisher Full Text | F1000 Recommendation

18. Collin M, Charles A, Barker A, et al:: Inflammatory myofibroblastic tumour of the bladder in children: a review. J Pediatr Urol. 2015; 11(5): 239-45. PubMed Abstract | Publisher Full Text

19. Applebaum H, Kieran MW, Cripe TP, et al.: The rationale for nonsteroidal anti-inflammatory drug therapy for inflammatory myofibroblastic tumors: a Children's Oncology Group study. J Pediatr Surg. 2005; 40(6): 999-1003. PubMed Abstract | Publisher Full Text

20. Chen H, Niu ZB, Yang Y: Bladder leiomyoma in a 6-year-old boy. Urology. 2012; 79(2): 434-6.

PubMed Abstract | Publisher Full Text

21. $\mathrm{F}$ Lu H, Male M, Jiang $\mathrm{K}$, et al.: Clinical significance of functional and anatomical classifications in paraganglioma of the urinary bladder. Urol Oncol. 2019; 37(6): 354.e9-354.e17.

PubMed Abstract | Publisher Full Text | F1000 Recommendation

22. $\mathrm{F}$ Bosserman AJ, Dai D, Lu Y: Imaging Characteristics of a Bladder Wall 
Paraganglioma. Clin Nucl Med. 2019; 44(1): 66-7.

PubMed Abstract | Publisher Full Text | F1000 Recommendation

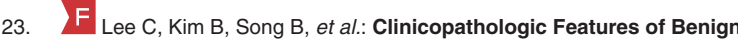
Neurogenic Tumor of Urinary Bladder. Int J Surg Pathol. 2018; 26(3): 221-8. PubMed Abstract | Publisher Full Text | F1000 Recommendation

24. Coughlin WF, Culliton M, Wood BP: Radiological case of the month. Neurofibromatosis of the bladder. Am J Dis Child. 1993; 147(7): 789-90. PubMed Abstract

25. Nguyen HT, Kogan BA, Hricak H, et al:: Plexiform neurofibroma involving the genitourinary tract in children: case reports and review of the literature. Urology. 1997; 49(2): 257-60.

PubMed Abstract | Publisher Full Text

26. deCou JM, Rao BN, Parham DM, et al: Malignant peripheral nerve sheath tumors: the St. Jude Children's Research Hospital experience. Ann Surg Oncol. 1995; 2(6): 524-9

PubMed Abstract | Publisher Full Text

27. Kunze E, Theuring F, Krüger G: Primary mesenchymal tumors of the urinary bladder. A histological and immunohistochemical study of 30 cases. Pathol Res Pract. 1994; 190(4): 311-32. PubMed Abstract | Publisher Full Text

28. Jahn $\mathrm{H}$, Nissen $\mathrm{HM}$ : Haemangioma of the urinary tract: review of the literature.
Br J Urol. 1991; 68(2): 113-7. PubMed Abstract | Publisher Full Text

29. Berrettini A, Castagnetti M, Salerno A, et al:: Bladder urothelial neoplasms in pediatric age: experience at three tertiary centers. J Pediatr Urol. 2015; 11(1): 26.e1-26.e5.

PubMed Abstract | Publisher Full Text

30. F Saltsman JA, Malek MM, Reuter VE, et al.: Urothelial neoplasms in pediatric and young adult patients: A large single-center series. J Pediatr Surg. 2018; 53(2): 306-9.

PubMed Abstract | Publisher Full Text | Free Full Text | F1000 Recommendation

31. F Pati A, Sahoo RK, Mahapatra A: Urothelial Carcinoma in Pediatric Patient. Indian J Surg. 2016; 78(3): 229-31.

PubMed Abstract | Publisher Full Text | Free Full Text | F1000 Recommendation

32. F Turcan D, Acikalin MF, Yilmaz E, et al: Nephrogenic adenoma of the urinary tract: A 6-year single center experience. Pathol Res Pract. 2017; 213(7): 831-5. PubMed Abstract | Publisher Full Text | F1000 Recommendation

33. Gleason JM, Bowlin PR, Bagli DJ, et al:: A comprehensive review of pediatric urachal anomalies and predictive analysis for adult urachal adenocarcinoma. J Urol. 2015; 193(2): 632-6.

PubMed Abstract | Publisher Full Text 


\section{Open Peer Review}

\section{Current Peer Review Status:}

\section{Editorial Note on the Review Process}

Faculty Reviews are review articles written by the prestigious Members of Faculty Opinions. The articles are commissioned and peer reviewed before publication to ensure that the final, published version is comprehensive and accessible. The reviewers who approved the final version are listed with their names and affiliations.

\section{The reviewers who approved this article are:}

\section{Version 1}

\section{Daniel Orbach}

SIREDO oncology center (Care, Innovation and Research for Children, Adolescents and Young Adults with cancer), Institut Curie, PSL university, Paris, France

Competing Interests: No competing interests were disclosed.

\section{Harry W. Herr}

Department of Urology, Memorial Sloan Kettering Cancer Center, Weill-Cornell Medical College, New York, NY, USA

Competing Interests: No competing interests were disclosed.

The benefits of publishing with F1000Research:

- Your article is published within days, with no editorial bias

- You can publish traditional articles, null/negative results, case reports, data notes and more

- The peer review process is transparent and collaborative

- Your article is indexed in PubMed after passing peer review

- Dedicated customer support at every stage

For pre-submission enquiries, contact research@f1000.com 